\title{
Long-Term Patency Rate of Radial Artery Conduits in Chinese Patients Undergoing Off-Pump Coronary Artery Bypass Grafting
}

\author{
Qiang Ji, ${ }^{1 *}$ MD, Kai Song, ${ }^{2 *}$ MD, JinQiang Shen, ${ }^{1}$, YuLin Wang, ${ }^{1}$ MD, Ye Yang, ${ }^{1}$ MD, \\ WenJun Ding, ${ }^{1} \mathrm{MD}, \mathrm{LiMin}$ Xia, ${ }^{1} \mathrm{MD}$ and ChunSheng Wang, ${ }^{2} \mathrm{MD}$
}

\begin{abstract}
Summary
Consensus has yet to emerge among experts as to whether the radial artery (RA) conduit was superior to the saphenous vein (SV) graft for coronary artery bypass grafting (CABG) in terms of long-term patency. This study aimed to evaluate long-term patency of the RA conduit compared to the SV conduit for off-pump CABG, and to screen the independent predictors of long-term RA graft failure.

Patients $<80$ years of age with graftable triple-vessel disease undergoing non-emergent, primary, isolated off-pump CABG, using both the RA and the SV conduits, were reviewed. Graft patency, all-cause mortality and repeat revascularization were followed-up. The independent predictors of long-term RA graft failure were identified.

A total of 296 out of 320 eligible patients (42 females, $61.3 \pm 9.9$ years old) received follow-up with an observed period of $93.4 \pm 16.5$ months. All-cause mortality was $14.5 \%$, and repeat revascularization was conducted on 6 RA grafts and $9 \mathrm{SV}$ grafts. Superior patency of the RA grafts compared to the SV grafts was observed $(84.4 \%$ versus $78.5 \%, P=0.035)$. Independent predictors of long-term RA graft failure included proximal stenosis of target right coronaries $<90 \%(\mathrm{OR}=2.35,95 \% \mathrm{CI} 1.41-5.82)$ and diabetes mellitus $(\mathrm{OR}=1.66$, 95\%CI 1.17-4.26).

The RA graft had a superior long-term patency than the SV graft. Long-term patency of the RA graft may be poor in diabetics or in the case of proximal stenosis of target right coronary <90\%. (Trial registration: ChiCTR-OCH-1200212)
\end{abstract}

(Int Heart J 2019; 60: 1276-1283)

Key words: Saphenous vein, Graft failure, Diabetics

$\mathrm{A}$ s early as 1971, the "skeletonized" radial artery (RA) was applied as a conduit for coronary artery bypass grafting (CABG), benefiting from a larger inner diameter relative to other arterial grafts, easy harvesting, and a lower incidence of wound infection. However, the incidence of vasospasm and functional occlusion of the RA conduit was as high as $35 \%$, resulting in a majority of cardiac surgeons abandoning the RA grafting for some years. ${ }^{1)}$ Afterwards, RA graft re-patency following early vasospasm and functional occlusion was found, wakening cardiac surgeons' interest in the RA grafting. ${ }^{2}$ Subsequently, the use of the RA as a bypass conduit for $\mathrm{CABG}$ was increasing.

Patency of the revascularization conduit was an essential predictor of long-standing survival following CABG surgery. Several previous reports supported the use of the RA conduit in preference to the saphenous vein
(SV) graft, ${ }^{3-10)}$ while other studies suggested the opposite. ${ }^{11-14)}$ Ongoing doubt and debate remained regarding the efficacy of the RA as an aorta-coronary conduit, with few solid data regarding long-term patency. Also, consensus has yet to emerge among experts as to whether the RA conduit was superior long-term patency to the SV graft.

In this study, 320 patients $<80$ years of age undergoing non-emergent primary isolated off-pump CABG with the use of both RA and SV grafts were reviewed and followed-up, in order to evaluate the long-term patency of the RA conduits compared to the SV grafts, and to screen the independent predictors of long-term RA graft failure.

\section{Methods}

Inclusion criteria: Patients $<80$ years of age with graftable triple-vessel disease and an estimated left ven-

From the ${ }^{1}$ Department of Cardiovascular Surgery, Zhongshan Hospital Fudan University, Shanghai, PR China and ${ }^{2}$ Shanghai Institute of Cardiovascular Disease, Shanghai, PR China.

*These authors contributed equally to this work.

This study was partly supported by the National Natural Science Foundation of China (Grant No. 81770341) and the Science and Technology Commission of Shanghai Municipality (Project Number: 14411967100).

Address for correspondence: ChunSheng Wang, MD, Shanghai Institute of Cardiovascular Disease, 1609 Xietu Road, Shanghai, 200032 , PR China. E-mail: zscardiacs2016@163.com or LiMin Xia, MD, Department of Cardiovascular Surgery, Zhongshan Hospital Fudan University, 180 Fenglin Road, Shanghai, 200032, PR China. E-mail: xlm1117@126.com

Received for publication May 14, 2018. Revised and accepted July 2, 2018

Released in advance online on J-STAGE November 15, 2019.

doi: 10.1536/ihj.18-305

All rights reserved by the International Heart Journal Association. 
tricular ejection fraction of more than $35 \%$ who received non-emergent, primary, isolated, off-pump CABG, who had both RA and SV grafts from January 2005 to December 2008 were eligible for this study. Patients with concomitant left ventricular aneurysm surgery, any concomitant acquired or congenital cardiac or aortic surgery, or concomitant malignancy were excluded. In addition, patients with hyperthyroidism, iodine contrast medium allergy, atrial fibrillation, and renal insufficiency may not be suitable candidates for coronary computer tomography (CT) angiographic examination, and thus, were not involved in the final analysis.

Study protocol: This study protocol was approved by the ethics committee of Zhongshan Hospital Fudan University and was consistent with the Declaration of Helsinki (Trial registration: ChiCTR-OCH-1200212). All included patients were followed-up for graft patency, all-cause mortality and repeat revascularization. ${ }^{15)}$ Graft patency was determined by non-invasive coronary CT angiography with a 64-slice, dual-source CT (iCT 64, Philips Healthcare, Amsterdam, Netherlands). If patients developed symptoms or doubtful symptoms of coronary heart disease during follow-up, non-invasive coronary CT angiography or invasive coronary angiography should be performed at the time; on the other hand, asymptomatic patients received non-invasive coronary CT angiography at the 13th month following surgery and then once every two years. Conduits were evaluated for failure $(\geq 50 \%$ lumen diameter reduction and/or reducing the caliber of distal anastomosis to $\geq 50 \%$ of the grafted coronary artery). A sequential conduit was divided into multiple segments according to the number of distal anastomoses. Each angiogram was independently adjudicated in a blinded fashion by two committee members, with a third review in the case of disagreement of the primary or secondary outcome. Also, in-hospital mortality, major postoperative morbidity, ${ }^{16)}$ and hands as well as arms complications potentially related to harvest of the RA conduits were recorded.

All patient follow-ups were divided into two groups: the failure group (RA graft failure) and the patency group (RA graft patency). Baseline characteristics, in-hospital and follow-up outcomes were compared between the two groups.

Surgical procedures and postoperative management: The pedicled RA was harvested from the antecubital fossa to the wrist in the arm, from the non-dominant arm, with the use of an electrocautery in an open fashion. After harvesting, the RA was rinsed and kept in a nitroglycerin and papaverin solution. The SV and the left internal mammary artery (LIMA) were harvested by the standard method. The target vessels for the RA conduits included the right coronary territory, the circumflex territory, the diagonal artery, and the left anterior descending coronary artery (LAD). The RA was bypass grafted to either the right or the left coronary territory, and the SV was used for the other territory besides the LAD. The target vessels for the RA conduits or the SV conduits had $>70 \%$ stenosis, were $>1.5 \mathrm{~mm}$ in diameter, and were deemed to be of acceptable quality according to visual assessment of the preoperative coronary angiogram by the operating surgeon. The detailed off-pump CABG procedure was referred to the related literature. ${ }^{17)}$ Surgeons were at liberty to choose sequential or separate RA or SV grafting for each case.

Subcutaneous injection of low molecular weight heparin within $6 \mathrm{~h}$ following surgery was performed routinely, except for patients undergoing re-operation for bleeding. Statin medication, aspirin, and clopidogrel were routinely prescribed to all patients starting from postoperative day 1 or 2 . Statin medication and aspirin were continued indefinitely, whereas clopidogrel was discontinued after one year. Also, patients received intravenous calcium channel blockers infusion at the beginning of the operation and continued for one day with concomitant oral calcium channel blockers overlap. After 24 hours, the intravenous infusion was discontinued, and the oral regimen maintained for one year.

Statistical analysis: Peri-operative data were obtained from our institutional database and reviewed using a standard data collection form. Follow-up data were obtained by telephone and clinic visit. Data collection was performed by trained staff (two people). The trained staff, however, did not know the purpose of the study.

Normally distributed continuous variables were expressed as the mean \pm standard deviation and were compared between groups using the Student's $t$-test. Nonnormally distributed continuous variables were expressed as median and compared between groups with the Wilcoxon rank sum test. Categorical variables were expressed as frequency distributions and single percentages and were compared between groups using $\chi^{2}$ test or Fisher's exact test, when appropriate. Cumulative graft patency was analyzed by the Kaplan-Meier method with the log-rank test for a comparison between the RA and the SV conduits. The independent predictors of long-term graft failure were identified using univariate analysis and then multivariate logistic regression with the backward method. A value of two-sided $P$ less than 0.05 was considered statistically significant. Statistical analysis was performed with SPSS statistical package version 22.0 (SPSS Inc., Chicago, IL, USA).

\section{Results}

Study population: A total of 358 patients meeting the inclusion criteria were included in this study. Thirty-eight patients were excluded (concomitant left ventricular aneurysm surgery in 5, concomitant malignancy in 5, concomitant hyperthyroidism in 1 , concomitant atrial fibrillation in 7 , and chronic renal dysfunction in 20), and finally 320 patients (42 females, $61.3 \pm 9.9$ years old) were analyzed. Baseline characteristics are shown in Table I. The number of distal anastomoses ranged from 3 to 6 (mean 3.8 per patient). Note that 9 patients $(2.8 \%)$ received LAD revascularization using RA conduits; $91.3 \%$ of patients received separate RA grafting, leaving 28 patients undergoing sequential RA grafting (from aorta to the diagonal and then to the circumflex territory). Further, $38.9 \%$ of RA conduits and $43.1 \%$ of SV conduits were grafted target coronary arteries with proximal stenosis $<90 \%(P=$ $0.260)$.

Clinical outcomes: In-hospital clinical outcomes are presented in Table II. In-hospital mortality was $1.6 \%$. The 
Table I. Baseline and Procedure Characteristics of the Cohort

\begin{tabular}{|c|c|}
\hline Parameter & Number of patients \\
\hline \multicolumn{2}{|l|}{ Demographics } \\
\hline Age (years) & $61.3 \pm 9.9$ \\
\hline Older age (age $>65$ years) & $111(34.7 \%)$ \\
\hline Gender (Female) & $42(13.1 \%)$ \\
\hline Obesity (Body mass index $>30 \mathrm{~kg} / \mathrm{m}^{2}$ ) & $36(11.3 \%)$ \\
\hline Recent smoking & $176(55.0 \%)$ \\
\hline \multicolumn{2}{|l|}{ Concomitant diseases } \\
\hline Diabetes mellitus & $116(36.3 \%)$ \\
\hline Hypertension & $228(71.3 \%)$ \\
\hline Prior cerebrovascular disease & $28(8.8 \%)$ \\
\hline Dyslipidemia & $167(52.2 \%)$ \\
\hline Peripheral vascular disease & $20(6.3 \%)$ \\
\hline Hepatic dysfunction* & $1(0.3 \%)$ \\
\hline COPD & $36(11.3 \%)$ \\
\hline Sleep apnea syndrome & $3(0.9 \%)$ \\
\hline Gout & $7(2.2 \%)$ \\
\hline Varicosis of great saphenous vein & $25(7.8 \%)$ \\
\hline History of carotid endarterectomy & $2(0.6 \%)$ \\
\hline \multicolumn{2}{|l|}{ Preoperative cardiac status } \\
\hline Remote MI & $29(9.1 \%)$ \\
\hline Recent $\mathrm{MI}^{\#}$ & $36(11.3 \%)$ \\
\hline Congestive heart failure (NYHA class III/IV) & $19(5.9 \%)$ \\
\hline \multicolumn{2}{|l|}{ CCS grade of angina } \\
\hline 1 & $7(2.2 \%)$ \\
\hline 2 & $77(24.1 \%)$ \\
\hline 3 & $152(47.5 \%)$ \\
\hline 4 & $84(26.2 \%)$ \\
\hline Left main trunk disease & $45(14.1 \%)$ \\
\hline History of PCI & $98(30.6 \%)$ \\
\hline $\operatorname{LVEF}(\%)$ & $51.3 \pm 10.9$ \\
\hline Impaired LV function $(\mathrm{LVEF}<0.5)$ & $143(44.7 \%)$ \\
\hline LVEDD (mm) & $54.0 \pm 7.6$ \\
\hline Large left ventricle (LVEDD > 65 mm) & $31(9.4 \%)$ \\
\hline \multicolumn{2}{|l|}{ Procedure characteristics } \\
\hline Off-pump CABG & $320(100 \%)$ \\
\hline Concomitant coronary endarterectomy & $5(1.6 \%)$ \\
\hline Intraoperative implantation of temporary pacemaker & $3(0.9 \%)$ \\
\hline Number of distal anastomosis & $3.8 \pm 0.8$ \\
\hline Use of LIMA-LAD & $311(97.2 \%)$ \\
\hline Use of RA & $320(100 \%)$ \\
\hline \multicolumn{2}{|l|}{ Target vessel stenosis } \\
\hline $70 \%-89 \%$ stenosis & $124(38.9 \%)$ \\
\hline $90 \%-99 \%$ stenosis & $135(42.2 \%)$ \\
\hline $100 \%$ stenosis & $61(19.1 \%)$ \\
\hline Sequential anastomosis & $28(8.8 \%)$ \\
\hline Grafting to diagonal and then to circumflex & 28 \\
\hline Single anastomosis & $292(91.2 \%)$ \\
\hline Grafting to LAD & 9 \\
\hline Grafting to diagonal artery & 30 \\
\hline Grafting to circumflex territory & 98 \\
\hline Grafting to right coronary territory & 155 \\
\hline Proximal coronary stenosis $<90 \%$ & 60 \\
\hline Proximal coronary stenosis $\geq 90 \%$ & 95 \\
\hline Use of SVG & $320(100 \%)$ \\
\hline \multicolumn{2}{|l|}{ Target vessel stenosis } \\
\hline $70 \%-89 \%$ stenosis & $138(43.1 \%)$ \\
\hline $90 \%-99 \%$ stenosis & $144(45.0 \%)$ \\
\hline $100 \%$ stenosis & $38(11.9 \%)$ \\
\hline Sequential anastomosis & $247(77.2 \%)$ \\
\hline Single anastomosis & $73(22.8 \%)$ \\
\hline
\end{tabular}

COPD indicates chronic obstructive pulmonary disease; MI, myocardial infarction; PCI, percutaneous cardiac intervention; LVEF, left ventricular ejection fraction; LVEDD, left ventricular endo-diastolic diameter; CABG, coronary artery bypass grafting; CPB, cardiopulmonary bypass; LM, left main coronary artery; LIMA, left internal mammary artery; RA, radial artery; LAD, left anterior descending coronary artery; and SVG, saphenous vein graft. *Hepatic dysfunction was recognized on the basis of Child-Pugh scores. "Recent MI: evidence of MI within the last 30 days before surgery. 
Table II. Clinical Outcomes

\begin{tabular}{lc}
\multicolumn{1}{c}{ Parameter } & Number of patients \\
\hline In-hospital & 320 \\
Number of patients & $5(1.6 \%)$ \\
In-hospital mortality & $11(3.4 \%)$ \\
New onset of MI & $6(1.9 \%)$ \\
IABP support & $7(2.2 \%)$ \\
Stroke & $12(3.8 \%)$ \\
Prolonged ventilation & $2(0.6 \%)$ \\
Requiring hemodialysis & $6(1.9 \%)$ \\
Re-operation for bleeding & $3(0.9 \%)$ \\
Deep sternal wound infection & \\
Follow-up & 296 \\
Number of patients & $43(14.5 \%)$ \\
All-cause mortality & 4 \\
Up to 1 year & 14 \\
1 year to 5 years & 25 \\
5 years to the last follow-up & $16(5.4 \%)$ \\
Repeat revascularization & 1 \\
Redo CABG & 15 \\
Percutaneous coronary intervention & 3 \\
RA graft + SV graft & 2 \\
RA graft & 6 \\
SV graft & 4 \\
Native coronaries distal to anastomosis & \\
\hline
\end{tabular}

MI indicates myocardial infarction; IABP, intra-aortic balloon pump; CABG, coronary artery bypass grafting; RA, radial artery; and SV, saphenous vein.

cause of death included cardiogenic death (2 cases), gastrointestinal hemorrhage (1), respiratory failure (1) and multiple organ failure caused by mediastinitis (1). One patient required readmission because of infection at the site where the RA was harvested. Thirty-one patients $(9.7 \%)$ reported moderate-to-severe symptoms of thenar paresthesia or numbness at discharge, and this number had decreased to three patients $(0.9 \%)$ within 12 months postoperatively. Six patients $(1.9 \%)$ reported moderate-to-severe weakness of the hand at discharge, and this number had decreased to only one patient at 12 months postoperatively. No hand claudication or ischemia was observed.

A total of 296 patients $(92.5 \%)$ received follow-up with an observed period of $93.4 \pm 16.5$ months. As shown in Table II, follow-up all-cause mortality was $14.5 \%$. Four patients died within one year following surgery, and the causes of death included myocardial infarction (1 case), infection (1), gastrointestinal hemorrhage (1) and pericardial effusion (1). Another 14 patients died within 13 months to five years following surgery, and the causes of death included myocardial infarction (2), heart failure (3), infection (4), hepatic failure (1), gastrointestinal hemorrhage (1) and malignant tumor (3). Over five years after surgery, 25 patients died; the main causes of death were listed as follows: myocardial infarction (3), heart failure (4), cerebral hemorrhage (2), gastrointestinal hemorrhage (1), infection (5), renal failure (1), malignant tumor (6), high falling injury (1) and traffic accident (2). Additionally, 16 patients underwent repeat revascularization, with the incidence of $5.4 \%$. Only 1 patient received repeat onpump CABG surgery due to complete occlusion of the RA graft from the aorta to the LAD. Intervention was conducted on 4 separate RA grafts (grafting to the right coronary territory in 3 and to the diagonal artery in 1) and 1 sequential RA graft between diagonal and obtuse marginal artery.

Graft patency: A total of 296 patients, including 320 RA grafts or segments (272 separate and 24 sequential grafts), $525 \mathrm{SV}$ grafts or segments (67 separate and 229 sequential grafts) and 292 LIMA grafts, received non-invasive coronary CT angiography during follow-up. Table III lists the long-term patency rate of grafts or segments. The RA grafts had a significantly higher patency as compared to the SV grafts $(84.4 \%$ versus $78.5 \%, P=0.035)$. Separate RA grafting to the right coronary territory with proximal native coronary stenosis $\geq 90 \%$ had a higher patency rate compared to $<90 \%$ ( $87.8 \%$ versus $68.4 \%, P=0.004)$. Separate or sequential RA grafting to the left coronary territories had a higher patency rate than separate RA grafting to the right coronary territory with proximal native coronary stenosis $<90 \%(87.2 \%$ versus $68.4 \%, P=$ $0.009 ; 89.6 \%$ versus $68.4 \%, P=0.003$, respectively). No significant difference was found in terms of the RA graft patency between concomitant sequential SV grafting and concomitant separate SV grafting $(84.3 \%$ versus $84.6 \%, P$ $=0.940)$. Also, the RA grafts had better cumulative patency rate than did the SV grafts in the Kaplan-Meier curve $\left(\chi^{2}=6.515\right.$, log-rank $\left.P=0.011\right)$ (Figure).

Risk factors for graft failure: Forty-eight patients who developed RA graft failure during follow-up were entered into the failure group, and the remaining 248 patients into the patency group. As presented in Table IV, significant differences were found between the two groups in gender (female versus male), recent smoking, concomitant with diabetes mellitus, the extent of proximal stenosis of target right coronary territory $(<90 \%$ versus $\geq 90 \%$ ), acute myocardial infarction associated with $\mathrm{CABG}$, and requiring hemodialysis. No significant difference was found between the two groups in terms of the RA grafting to the right coronary territory versus the RA grafting to the left coronary system $(P=0.098)$. Those variables with $P<$ 0.10 obtained in univariate analysis were then entered into a multivariable logistic regression analysis to identify the independent risk factors for long-term RA graft failure. As shown in Table $\mathrm{V}$, proximal stenosis of target right coronary territory $<90 \%(\mathrm{OR}=2.35,95 \% \mathrm{CI} 1.41-5.82, P=$ $0.008)$ and concomitant with diabetes mellitus $(\mathrm{OR}=$ $1.66,95 \%$ CI $1.17-4.26, P=0.032$ ) were two independent risk factors for long-term RA graft failure. In the same way, independent risk factors for long-term SV graft failure included concomitant with dyslipidemia $(\mathrm{OR}=3.12$, 95\%CI 1.71-7.36, $P=0.002)$ and concomitant with diabetes mellitus $(\mathrm{OR}=1.51,95 \% \mathrm{CI} 1.15-4.01, P=0.043)$.

\section{Discussion}

The major finding of this study was that the RA grafts had a superior long-term patency rate to the SV grafts. In this study, we investigated target coronary arteries with proximal stenosis $<90 \%$. There was no significant difference between the RA grafts and the SV grafts. Therefore, we can infer that the differences in long-term graft patency between the RA grafts and the SV grafts 
Table III. Graft Failure (Patency Rate) Determined by CT Angiography

\begin{tabular}{lc}
\hline \multicolumn{1}{c}{ Grafts } & Number of failure (Patency rate) \\
\hline LIMA grafts & $17(275 / 292=94.2 \%)$ \\
RA grafts or segments & $50(270 / 320=84.4 \%)$ \\
Sequential RA segments & $5(43 / 48=89.6 \%)$ \\
Separate RA grafts & $45(227 / 272=83.4 \%)$ \\
$\quad$ Grafting to left coronaries & $16(109 / 125=87.2 \%)$ \\
Grafting to right coronaries & $29(118 / 147=80.3 \%)$ \\
$\quad<90 \%$ proximal stenosis of target coronaries & $18(39 / 57=68.4 \%)$ \\
$\geq 90 \%$ proximal stenosis of target coronaries & $11(79 / 90=87.8 \%)$ \\
SV grafts or segments & $113(412 / 525=78.5 \%)$ \\
Sequential SV segments & $93(365 / 458=79.7 \%)$ \\
Concomitant RA graft failure & $36(193 / 229=84.3 \%)$ \\
Separate SV grafts & $20(47 / 67=70.1 \%)$ \\
Concomitant RA graft failure* & $14(77 / 91=84.6 \%)$ \\
\hline
\end{tabular}

CT indicates computed tomography; LIMA, left internal mammary artery; RA, radial artery; and SV, saphenous vein. "Concomitant RA graft failure, RA graft failure in the case of patients undergoing concomitant sequential SV grafting; * Concomitant RA graft failure, RA graft failure in the case of patients undergoing concomitant separate SV grafting.

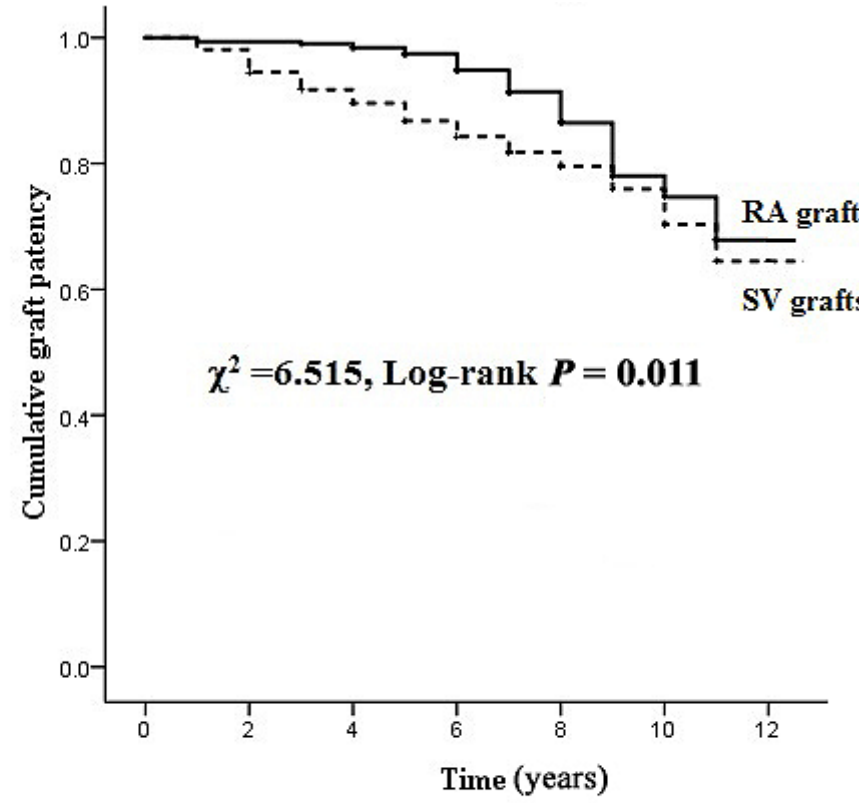

\section{Grafts at risk}

$\begin{array}{lllllll}\text { RA grafts } & 320 & 318 & 307 & 251 & 103 & 22 \\ \text { SV grafts } & 525 & 486 & 446 & 342 & 133 & 24\end{array}$

Figure. Cumulative patency of RA grafts versus SV grafts. RA indicates radial artery; and SV, saphenous vein.

could not be related to proximal stenosis of target vessels. This study reported long-term RA graft patency of $84.4 \%$, which was significantly higher than the SV graft. And results of this study showed that the RA graft had superior cumulative patency than did the SV graft. These results suggested that the RA graft was superior to the SV graft in terms of long-term patency. Several previous studies reported the mid- to long-term patency of the RA graft. Buxton and colleagues ${ }^{18)}$ reported the RA graft received a similar five-year's patency with the SV graft in a prospective, randomized study. A multicenter clinical trial ${ }^{19)}$ showed that the RA and the SV grafts received similar incidence of complete graft occlusion at one year (11\%). Nevertheless, most previous reports supported the use of the RA conduit instead of the SV graft. Zacharias and colleagues $^{20)}$ evaluated the 6-year's clinical outcomes of propensity-matched patients undergoing LIMA-to-LAD with either an additional RA graft or SV graft as the second conduit, and showed a trend toward higher RA graft patency. Desai and colleagues ${ }^{21}$ in the first multicenter clinical trial (Radial Artery Patency Study) showed that the RA graft had a protective effect against occlusion 
Table IV. Clinical Data of Failure Group versus Patency Group

\begin{tabular}{|c|c|c|c|}
\hline & Failure group $(n=48)$ & Patency group $(n=248)$ & $P$ value \\
\hline \multicolumn{4}{|l|}{ Preoperative data } \\
\hline Older age & $15(31.3 \%)$ & $87(35.1 \%)$ & 0.609 \\
\hline Gender (Female) & $11(22.9 \%)$ & $28(11.3 \%)$ & 0.029 \\
\hline Obesity & $9(18.8 \%)$ & $25(10.1 \%)$ & 0.085 \\
\hline Recent smoking & $33(68.8 \%)$ & $132(53.2 \%)$ & 0.047 \\
\hline Diabetes mellitus & $27(56.3 \%)$ & $83(33.5 \%)$ & 0.003 \\
\hline Hypertension & $39(81.3 \%)$ & $173(69.8 \%)$ & 0.106 \\
\hline Prior cerebrovascular disease & $5(10.4 \%)$ & $21(8.5 \%)$ & 0.662 \\
\hline Dyslipidemia & $30(62.5 \%)$ & $127(51.2 \%)$ & 0.151 \\
\hline Peripheral vascular disease & $3(6.3 \%)$ & $15(6.0 \%)$ & 1.000 \\
\hline COPD & $6(12.5 \%)$ & $28(11.3 \%)$ & 0.810 \\
\hline Prior MI & $11(22.9 \%)$ & $50(20.2 \%)$ & 0.666 \\
\hline Congestive heart failure & $3(6.3 \%)$ & $14(5.6 \%)$ & 0.744 \\
\hline Left main trunk disease & $7(14.6 \%)$ & $35(14.1 \%)$ & 0.932 \\
\hline History of PCI & $15(31.3 \%)$ & $75(30.2 \%)$ & 0.889 \\
\hline Impaired LV function & $23(47.9 \%)$ & $112(45.2 \%)$ & 0.726 \\
\hline Large left ventricle & $5(10.4 \%)$ & $24(9.7 \%)$ & 0.795 \\
\hline \multicolumn{4}{|l|}{ Intraoperative data } \\
\hline Number of distal anastomosis & $3.7 \pm 0.7$ & $3.8 \pm 0.8$ & 0.420 \\
\hline Use of LIMA & $45(93.8 \%)$ & $242(97.6 \%)$ & 0.157 \\
\hline Use of RA & $48(100 \%)$ & $248(100 \%)$ & \\
\hline Sequential anastomosis & $3(6.3 \%)$ & $21(8.5 \%)$ & 0.777 \\
\hline Single anastomosis & $45(93.8 \%)$ & $227(91.5 \%)$ & \\
\hline Grafting to left coronaries & $16(35.6 \%)$ & $109(48.0 \%)$ & 0.125 \\
\hline Grafting to right coronaries & $29(64.4 \%)$ & $118(52.0 \%)$ & \\
\hline$\geq 90 \%$ proximal stenosis & $11(37.9 \%)$ & $79(66.9 \%)$ & 0.004 \\
\hline$<90 \%$ proximal stenosis & $18(62.1 \%)$ & $39(33.1 \%)$ & \\
\hline Target vessels of RA & $48(100 \%)$ & $248(100 \%)$ & \\
\hline Right coronaries & $29(60.4 \%)$ & $118(47.6 \%)$ & 0.098 \\
\hline Left coronaries & $19(39.6 \%)$ & $130(52.4 \%)$ & \\
\hline Separate grafting to LAD & 1 & 8 & 0.425 \\
\hline Separate grafting to $\mathrm{D}$ & 6 & 22 & \\
\hline Separate grafting to $\mathrm{OM}$ & 9 & 79 & \\
\hline Sequential grafting to D-OM & 3 & 21 & \\
\hline Use of SVG & $48(100 \%)$ & $248(100 \%)$ & \\
\hline Sequential anastomosis & $36(75.0 \%)$ & $191(77.0 \%)$ & 0.762 \\
\hline Single anastomosis & $12(25.0 \%)$ & $57(23.0 \%)$ & \\
\hline \multicolumn{4}{|l|}{ Early postoperative data } \\
\hline In-hospital mortality & 0 & 0 & \\
\hline New onset of MI & $4(8.3 \%)$ & $4(1.6 \%)$ & 0.026 \\
\hline Stroke & $1(2.1 \%)$ & $5(2.0 \%)$ & 1.000 \\
\hline Prolonged ventilation & $2(4.2 \%)$ & $6(2.4 \%)$ & 0.620 \\
\hline Requiring hemodialysis & $2(4.2 \%)$ & 0 & 0.001 \\
\hline Re-operation for bleeding & $1(2.1 \%)$ & $4(1.6 \%)$ & 0.590 \\
\hline Deep sternal wound infection & $1(2.1 \%)$ & $1(0.4 \%)$ & 0.298 \\
\hline
\end{tabular}

Failure group indicates patients receiving radial artery graft failure during follow-up; patency group, patients receiving radial artery graft patency during follow-up; COPD, chronic obstructive pulmonary disease; MI, myocardial infarction; PCI, percutanous coronary intervention; LV, left ventricle; LIMA, left internal mammary artery; RA, radial artery; and SVG, saphenous vein graft.

through comparing angiographic data of 440 RA grafts with $440 \mathrm{SV}$ grafts for more than five years. The singlecenter Radial Artery Versus Saphenous Vein Patency trial (RSVP trial) reported that complete graft occlusion was markedly less frequent in the RA graft compared with the SV graft. $^{3)}$ Deb and colleagues ${ }^{7)}$ updated Athanasiou's review with results from the RAPS study and new data, and found that the RA graft, compared to the SV graft, was associated with reduced graft failure more than five years after isolated $\mathrm{CABG}$ surgery. These pieces of evidence were consistent with results of this study.
Another important finding was that proximal stenosis of target right coronary territory $<90 \%$ and concomitant with diabetes mellitus were two independent predictors of long-term RA graft failure. Data from this study showed separate RA grafting to the right coronaries with proximal stenosis $\geq 90 \%$ compared to $<90 \%$ had a higher patency rate, and the risk of RA graft failure in patients with proximal stenosis of target right coronaries $<90 \%$ was 2.35 times than that in patients with proximal stenosis of target right coronaries $\geq 90 \%$, suggesting that the more serious proximal stenosis of target right coronaries, the 
Table V. Independent Predictors of Long-Term RA Graft Failure

\begin{tabular}{lccc}
\hline \multicolumn{1}{c}{ Variable } & OR & 95\%CI & $P$ value \\
\hline Gender (female versus male) & 1.89 & $0.91-4.48$ & 0.087 \\
Recent smoking & 1.33 & $0.89-2.96$ & 0.361 \\
Diabetes mellitus & 1.66 & $1.17-4.26$ & 0.032 \\
Proximal stenosis of target right coronaries < 90\% & 2.35 & $1.41-5.82$ & 0.008 \\
Target vessels of RA (right versus left coronaries) & 1.48 & $0.92-3.15$ & 0.078 \\
Perioperative MI associated CABG & 3.12 & $0.83-6.14$ & 0.163 \\
Postoperative RF requiring hemodialysis & 2.13 & $0.91-4.67$ & 0.081 \\
\hline
\end{tabular}

OR indicates odd ratio; $\mathrm{CI}$, confidence interval; $\mathrm{MI}$, myocardial infarction; $\mathrm{CABG}$, coronary artery bypass grafting; and RF, renal failure.

higher RA graft patency. Desai and colleagues ${ }^{21)}$ reported that grafting to a vessel with proximal occlusion improved the RA patency. The single-center RSVP study ${ }^{3)}$ also reported that graft patency was improved when the RA was directed to a more severely narrowed target vessel. A meta-analysis ${ }^{22}$ showed that patients with severe proximal stenosis may have better mid-term patency after the RA bypass grafting. This evidence was in line with results of this study. The reason may be related to blood flow competition between the RA graft and target coronaries. ${ }^{3,5,20,22)}$ Certain characteristics of the RA, including the increased wall thickness and the density and organization of myocytes, may increase the propensity of this artery for spasm when there was decreased or competitive flow. ${ }^{23)}$ Also, this study showed that diabetes mellitus was an independent predictor of RA graft failure. The reason of that may be that diabetes mellitus was responsible for acceleration and worsening of atherothrombosis. ${ }^{24)}$ In addition, results of this study showed that, besides concomitant with diabetes mellitus, proximal stenosis for the target right coronary territory $<90 \%$ was an independent risk factor for longterm RA graft failure, whereas concomitant with dyslipidemia was an independent predictors of long-term SV graft failure. Our results suggested that blood flow competition played an important role in the development of RA graft failure but had no obvious effect on the development of SV graft failure; and hyperlipidemia, the major risk factor of causing atherosclerosis, ${ }^{25)}$ had significant effects on the progress of SV graft failure. The reason for this difference may be related to the different physiological characteristics between the muscular artery and the vein.

It was also important to keep in mind that the RA bypass grafting was not indicated for all patients. Patients with a positive Allen's test, a history of Raynaud's syndrome or vasculitis, or inadequate ulnar compensation, as determined by non-invasive Doppler vascular ultrasound, may not be suitable candidates for the RA bypass grafting. Patients with widespread atherosclerotic coronary anastomosis regions and/or widespread atherosclerotic distal regions of the target coronaries were not suitable candidates for the RA grafting. Also, the ideal target vessel for the RA grafting may be a reasonably sized $(>1.5 \mathrm{~mm})$ coronary artery with preferable $\geq 90 \%$ proximal native coronary stenosis in non-diabetic patients. The decision about the use of the RA graft should be tailored individually in order to achieve the greatest clinical benefit for patients.

The RA patency after off-pump CABG did not trans- late into the RA patency following on-pump CABG. Offpump coronary bypass surgery, compared to on-pump, may have an adverse effect on anastomotic patency, ${ }^{26)}$ resulting in potentially inferior RA patency after off-pump CABG. However, we did not have enough data to identify the RA patency after on-pump CABG. Despite over 1000 cases of $\mathrm{CABG}$ procedure annually in our institution, more than $95 \%$ of isolated CABG procedure were conducted without cardiopulmonary bypass, and few patients received on-pump RA grafting. Whether there were differences in the RA patency between off-pump and on-pump CABG needed prospective and multicenter studies involving large sample size. In particular, it should be included data from the major medical centers in which off-pump CABG was the predominant method of surgical revascularization.

Note that the prevalence rate of recent smoking was up to $55.0 \%$ in this cohort, with far above $30 \%$ in the Western countries reports. ${ }^{27,28)}$ Although the public gradually raised awareness of the dangers of smoking, and Chinese government attached great importance to tobacco control, the prevalence rate of smoking in China remains unacceptably high in the current era. ${ }^{28}$ So far, China has become the largest tobacco producer and consumer in the world, with more than 300 million smokers. ${ }^{29)}$ This study suggested that tobacco control have not advanced very far, and more measures were needed.

There are several limitations of this study. First, it was a single-center study with a limited sample size. A final determination of effect would need a multicenter study involving a larger sample size. Second, non-invasive coronary CT angiography was used to determine the patency of the RA and the SV grafts. Non-invasive coronary CT angiography may be less accurate for assessing graft patency than invasive coronary angiography, but it is the more favorable choice of patients who schedule for an examination of graft patency. ${ }^{30)}$ Third, angiographic data were limited, and we could not ascertain the inner diameter of the RA, the SV, and target coronaries. Finally, the follow-up duration in this study was relatively short (eight years or so), which may lead to the underestimation of net benefit of the RA grafting in comparison with the SV grafting.

\section{Conclusions}

The RA graft had a superior long-term patency than did the SV graft. Long-term patency of the RA graft may 
be poor in diabetic patients or in the case of proximal stenosis of target right coronaries $<90 \%$.

\section{Disclosure}

Conflicts of interest: None.

\section{References}

1. Carpentier A, Guermonprez JL, Deloche A, Frechette C, DuBost C. The aorta-to-coronary radial artery bypass graft. A technique avoiding pathological changes in grafts. Ann Thorac Surg 1973; 16: 111-21.

2. Nicolini F, Agostinelli A, Spaggiari I, et al. Current trends in surgical revascularization of multivessel coronary artery disease with arterial grafts. Int Heart J 2014; 55: 381-5.

3. Collins P, Webb CM, Chong CF, Moat NE, Radial Artery Versus Saphenous Vein Patency (RSVP) Trial Investigators. Radial artery versus saphenous vein patency randomized trial: five-year angiographic follow-up. Circulation 2008; 117: 2859-64.

4. Tranbaugh RF, Dimitrova KR, Friedmann P, et al. Radial artery conduits improve long-term survival after coronary artery bypass grafting. Ann Thorac Surg 2010; 90: 1165-72.

5. Yie K, Na CY, Oh SS, Kim JH, Shinn SH, Seo HJ. Angiographic results of the radial artery graft patency according to the degree of native coronary stenosis. Eur J Cardiothorac Surg 2008; 33: 341-8.

6. Amano A, Hirose H, Takahashi A, Nagano N. Coronary artery bypass grafting using the radial artery: midterm results in a Japanese institute. Ann Thorac Surg 2001; 72: 120-5.

7. Deb S, Cohen EA, Singh SK, et al. Radial artery and saphenous vein patency more than 5 years after coronary artery bypass surgery: results from RAPS (Radial Artery Patency Study). J Am Coll Cardiol 2012; 60: 28-35.

8. Ummarino D. Surgery: reliability of radial artery in CABG surgery. Nat Rev Cardiol 2016; 13: 570.

9. Shi WY, Tatoulis J, Newcomb AE, Rosalion A, Fuller JA, Buxton BF. Is a third arterial conduit necessary? Comparison of the radial artery and saphenous vein in patients receiving bilateral internal thoracic arteries for triple vessel coronary disease. Eur J Cardiothorac Surg 2016; 50: 53-60.

10. Rehman SM, Yi G, Taggart DP. The radial artery: current concepts on its use in coronary artery revascularization. Ann Thorac Surg 2013; 96: 1900-9.

11. Hortmann HC, Oliveira HG, Rabello RR, Rocha EA, Oliveira $\mathrm{SC}$. Comparison of patency between radial artery and saphenous vein in a coronary artery bypass grafting postoperative with return of the symptoms. Rev Bras Cir Cardiovasc 2010; 25: 218-23.

12. Nicolini F, Vezzani A, Romano G, et al. Coronary artery bypass grafting with arterial conduits in the elderly. Int Heart J 2017; 58: 647-53.

13. Yoshida S, Numata S, Tsutsumi Y, et al. Short- and long-term results of radial artery and saphenous vein grafts in the right coronary system: a propensity-matched study. Surg Today 2017; 47: 335-43.

14. Petrovic I, Nezic D, Peric M, et al. Radial artery vs saphenous vein graft used as the second conduit for surgical myocardial revascularization: long-term clinical follow-up. J Cardiothorac Surg 2015; 10: 127.

15. Ji Q, Shi Y, Xia L, et al. Revascularization of left coronary system using a skeletonized left internal mammary artery -sequential vs. separate grafting. Circ J 2017; 82: 102-9.

16. Ji Q, Lai H, Sun Y, et al. Impact of presurgical mild acute respiratory distress syndrome on surgical mortality after surgical repair of acute type A aortic dissection. Int Heart J 2017; 58: $739-45$.

17. Xia L, Ji Q, Song K, et al. Early clinical outcomes of on-pump beating-heart versus off-pump technique for surgical revascularization in patients with severe left ventricular dysfunction: the experience of a single center. J Cardiothorac Surg 2017; 12: 11.

18. Buxton BF, Raman JS, Ruengsakulrach $\mathrm{P}$, et al. Radial artery patency and clinical outcomes: five-year interim results of a randomized trial. J Thorac Cardiovasc Surg 2003; 125: 1363-71.

19. Goldman S, Sethi GK, Holman W, et al. Radial artery grafts vs saphenous vein grafts in coronary artery bypass surgery: a randomized trial. JAMA 2011; 305: 167-74.

20. Zacharias A, Schwann TA, Riordan CJ, Durham SJ, Shah AS, Habib RH. Late results of conventional versus all-arterial revascularization based on internal thoracic and radial artery grafting. Ann Thorac Surg 2009; 87: 19-26.e2.

21. Desai ND, Naylor CD, Kiss A, et al. Impact of patient and target-vessel characteristics on arterial and venous bypass graft patency: insight from a randomized trial. Circulation 2007; 115: 684-91.

22. Cao C, Ang SC, Wolak K, Peeceeyen S, Bannon P, Yan TD. A meta-analysis of randomized controlled trials on mid-term angiographic outcomes for radial artery versus saphenous vein in coronary artery bypass graft surgery. Ann Cardiothorac Surg 2013; 2: 401-7.

23. Desai ND, Cohen EA, Naylor CD, Fremes SE, Radial Artery Patency Study Investigators. A randomized comparison of radial-artery and saphenous-vein coronary bypass grafts. N Engl J Med 2004; 351: 2302-9.

24. Hoffman DM, Dimitrova KR, Lucido DJ, et al. Optimal conduit for diabetic patients: propensity analysis of radial and right internal thoracic arteries. Ann Thorac Surg 2014; 98: 30-6; discussion 36-7.

25. Nimkuntod P, Tongdee P. Association between subclinical atherosclerosis among hyperlipidemia and healthy subjects. J Med Assoc Thai 2015; 98: S51-7.

26. Kajimoto K, Yamamoto T, Amano A. Is off-pump CABG really inferior to on-pump strategies for long-term survival? J Am Coll Cardiol 2014; 64: 1181.

27. Van Domburg RT, op Reimer WS, Hoeks SE, Kappetein AP, Bogers AJ. Three life-years gained from smoking cessation after coronary artery bypass surgery: a 30-year follow-up study. Am Heart J 2008; 156: 473-6.

28. Benedetto U, Albanese A, Kattach H, et al. Smoking Cessation before coronary artery bypass grafting improves operative outcomes. J Thorac Cardiovasc Surg 2014; 148: 468-74.

29. Gu D, Kelly TN, Wu X, et al. Mortality attributable to smoking in China. N Engl J Med 2009; 360: 150-9.

30. Weustink AC, Nieman K, Pugliese F, et al. Diagnostic accuracy of computed tomography angiography in patients after bypass grafting: comparison with invasive coronary angiography. JACC Cardiovasc Imaging 2009; 2: 816-24. 